\title{
Techniques of Online Propaganda: A Case Study of Western Sahara Conflict
}

\author{
Sidi Sidi Mohamed Hamdani \\ Mohammed V University, Rabat, Morocco \\ E: hamdani.mohamed@isiam.ma
}

Article Info:

Received 11 November 2017

Accepted 17 April 2018

Published 15 July 2018

DOI: https://doi.org/10.12973/ojcmt/2653

The role of the Internet in the proliferation of propaganda during conflicts has growingly assumed an increasing importance to those aiming at garnering public support for a political conflict. With a ceasefire brokered in 1991 by the United Nations, the conflict of Western Sahara shifted from the battles on the ground to a frenzy war in the mass media. The Internet has hitherto served as a significant new resource for politicians, media managers and propagandists from both conflicting sides to engender propaganda in its different forms. Both Morocco and the Polisario have been active in this respect, utilizing propaganda strategies and techniques to manipulate the war of information on the Net. In the literature about propaganda, it is common to refer to the seven propaganda techniques defined by the Institute for Propaganda Analysis (IPA) founded in 1937: card stacking, name-calling, glittering generality, transfer, testimonial, plain folks, and bandwagon. Using the case of Western Sahara conflict, the goal of this study is to gain insight into those seven techniques in online propaganda messages. The focus is put on the propaganda campaign launched on the Internet by Morocco and the Polisario on many occasions during the conflict.

Keywords: Western Sahara, propaganda, internet

\section{INTRODUCTION}

Almost 42 years have passed since Spain left its former colony and transferred it to Morocco, Western Sahara dossier remains open in the United Nations and stands out as one of the most intractable political conflicts in Africa. Morocco and the Polisario Front waged war for a decade during most of the 1980s until 1991. The year 1991, indeed, was a turning point in the chronology of the conflict.

With a ceasefire brokered in 1991 by the UN, the conflict shifted from the fighting on the ground to the realm of cyberspace by making use of innovations in information technology. The development and employment of "information warfare," loomed as a potent new warfare technique that was effectively used by both conflicting parties to disseminate online propaganda. The anonymity and unrestricted nature of the World Wide Web has become a new back up mechanism for outgunned fighters. A number of pro-Morocco and pro-Polisario websites have been created. Many of them are constructed in many languages to address not only the local people but people from all over the world. Owners and designers of those websites are mostly non- governmental organizations and supporters of one side while others are government- 
sponsored websites. These include some popular pro-Morocco websites such as corcas.com, the voice of the Royal Advisory Council for Saharan Affairs (CORCAS); an advisory committee to the Moroccan government on Western Sahara and other pro-Polisario websites like spsrasd.info, a website sponsored by the Sahara Press service (SPS), a news agency controlled by Polisario and based in the Algerian refugee camps.

This mechanism has developed a new system to manipulate the public perception of the conflict. Both Morocco and the Polisario Front started different tactics to adapt to a new media environment in which they can have monopoly on information about events inside and outside the region. A frenzy campaign of propaganda has been launched through the Internet. The range of the campaign is wide, encompassing an extreme use of propaganda in its different forms, strategies and techniques.

Using the case of Western Sahara conflict, this article intends to explore mainly the techniques of propaganda employed in both Morocco and Polisario sponsored websites. The focus is put on the techniques developed by the Institute for Propaganda Analysis (IPA). The IPA identified seven propaganda devices: name calling, glittering generality, transfer, testimonial, plain folks, card stacking, and bandwagon (Severin and Tankard, 1992: 93-104). The aim here is to spot those techniques in both pro-Polisaro and pro-Morocco websites. The study doesn't opt for specific event. It focuses on a number of incidents in which the seven techniques are utilized by conflicting parties. However, the period covered for the study starts from January, 2010 through December, 2016.

\section{The IPA Propaganda Techniques}

When analysing propaganda, researchers often draw on Lee and Lee's (1939) propaganda techniques to recognize the strategies used by the propagandist to control public opinion. These techniques were cited in a book titled The Fine Art of Propaganda and published by the Institute for Propaganda Analysis (IPA), founded in 1937 by a group of top names in communication research including Jowett, Hadley Cantril, Lee and Lee, Sproule, Leonard Doob, Robert Lynd, Edgar Dale and many others. (IPA) aimed at teaching the Americans how to recognize propaganda techniques. Although it was short-lived, the Institute managed to generate a list of propaganda techniques that have become typical in mass media and continued to be employed extensively in our contemporary era. Allen made use of these techniques to call attention to the way how President George W. Bush employs religious rhetoric in his speeches after the attacks of September 11, 2001 (Allen 2002: 41-49).

With the advent of the Institute for Propaganda Analysis (IPA), propaganda analysis became identical with its recognized seven common propaganda devices: name calling, glittering generalities, card stacking, and so forth (Sproule 1997:129-137). For our purposes in propaganda analysis, inspired by the work of the IPA, this article aims at locating the seven techniques in both pro-Polisario and pro-Morocco websites. The following is an explanation of these techniques of propaganda.

A qualitative content analysis is used to ensure a consistent comparability between two contradicted discourses. The content analysis is used as one of the main techniques of comparative analysis appropriate for spotting differences and similarities (Kleinsteuber, 2004: 64-86). The approach is here mainly meant to spot differences and similarities between proPolisario and pro-Morocco discourses. The content analysis is also an effective technique for making inferences by systematically and objectively identifying special characteristics of the message (Berger, 1991:107).

The study deals with the daily content posted on the homepages of the websites under study 
Using the case of Western Sahara conflict, the goal of this study is to gain insight into those seven techniques in online propaganda messages. The focus is put on the propaganda campaign launched on the Internet by Morocco and the Polisario on many occasions during the conflict. The study focuses on the period from January 2010 to June 2013

\section{Method of Selecting Websites}

Imperative to the development of this work is the selection of a number of websites to be studied. A list of a representative sample of key websites containing content regarding the issue of Western Sahara conflict has been identified according the following methods.

The researcher conducted a survey and in-depth interviews from January 2010 to July 2010 covering 192 respondents from the following major Western Saharan cities: Laayoune, Essmara, and Dakhla. Most of surveys were sent via emails to respondents who proved being active in some Facebook groups dealing with content related to Western Sahara conflict. The survey hoped to gather information on pro-Morocco and pro-Polisario websites, use and frequency of their visit by respondents. Respondents were asked to indicate a number of pro-Morocco and proPolisario websites they often visited to obtain information about the Western Sahara conflict. Of 16 websites listed by respondents, more than half were opted for the following pro-Polisario websites: spsrasd.info and upes.org as well as pro-Morocco websites such as corcas.com .

The study considered those websites which explicitly identify themselves as the official websites that represent the voice of conflicting parties or tend to back or adopt their ideologies. Both spsrasd.info and upes.org identify themselves as official pro-Polisario websites as they are openly represented and managed by known persons from the Polisario. Similarly, corcas.com is a website that officially represents a pro-Morocco body meant to issue advisory opinions to the Moroccan government on the Western Sahara. This is by no means an exhaustive list, but one that can provide a cross-section of our target websites that can be found online.

The purpose of this study is to specifically pinpoint some examples of the seven propaganda techniques defined by the Institute for Propaganda Analysis (IPA) in the content of both proPolisario and pro-Morocco websites under study. The study opted for no specific event but focused on a number of cases since the start of the study in January, 2010 through December, 2016 in an attempt to demonstrate the use of the seven techniques by propagandists from conflicting sides, Morocco and the Polisario. In the regard, the study managed to substantiates that a great amount of those propaganda techniques has been effectively employed on the internet by both opposing sides in their websites as an attempt to manipulate the public opinion

\section{Propaganda Analysis}

Using the case of the Sahara, both Morocco and the Polisario seem to have evinced a shrewd grasp of the utility of propaganda as an instrument of shaping the perception of the conflict in the minds of their target audiences. Propaganda techniques have been utilised to fulfil this goal particularly during periods of political crises when frenzy campaigns of propaganda are usually launched. All through the conflict, a fair amount of those techniques has been effectively employed on the Internet by both opposing sides as an attempt to manipulate the public opinion. The focus of this study will put on the period starting from January, 2010 till the December, 2016.

Name calling was one of the most prevalent devices identified in both pro-Morocco and proPolisario websites. It is one of the seven devices identified by the Institute for Propaganda Analysis. According to Lee and Lee (1939) name-calling is when an idea is given a bad label and it is employed to make people refuse and criticize without scrutinizing the proof (p. 26). The technique was used to provoke prejudices in the target audience by labeling the opponent as something the addressees fear, abhor, and find disagreeable, in this regard, the Polisario are usually labelled on the pro-Morocco websites as "Mercenaries", "Dissidents", "Militias", and "Enemies of territorial unity" and so on. In some cases, the Polisario is referred to as a "terrorist 
group" . These labels have strong implications for neutralizing the opponent and send an alarming admonition to those who might follow in their path. The camps of Tindouf, governed by the Polisario front, are also dubbed by "Camps of shame" and "concentration camps" where tens of thousands Sahrawi citizens have been "sequestrated" or "warehoused" since more than three decades. The technique of Name Calling associates the place with offensive names that may appeal to emotional prejudices by creating sympathy with the people living there or instilling fear among audiences by labelling the place as an "unsafe destination". Similarly, not surprisingly, Name Calling seemed to be present in most of pro-Polisario websites. Moroccans were given judgmental names such as "Invaders", "Settlers" and "The enemy". The Moroccan security forces are also referred to as "oppressive forces". Calling Morocco, a "Tyrannical regime", is meant to an attempt to judge the whole government and then legitimize hostility against it.

Glittering Generality is the second most popular technique employed by both Moroccan and Polisario political propaganda practitioners on their websites. A glittering generality is something linked to a virtue and it employed to make people acknowledge and accept an idea without questioning the proof (Lee \& Lee 1939: 47). A glittering generality, Name Calling in reverse, makes use of words that we all support or believe in. A word like democracy, for example, usually carries a universal meaning that when we name a nation a democratic, we often glorify it. On most occasions, the Polisario referrers to Western Sahara conflict as "struggle for freedom and independence" . On the other hand, Morocco sees the conflict of the Sahara as an issue of "national sovereignty" and "historical legitimacy". For Morocco, the threats come from the Polisario which is challenging the "territorial integrity" and "unity" of the kingdom. These virtue words usually have positive connotations to people since they are linked to something they value and serve as a way to legitimize the stances of conflicting parties on the issue and persuade people to develop positive feeling and judgment to approve of the claimed "legal rights" of rivals. Glittering Generalities are also used in the form of certain symbols or slogans so that the audience memorizes them easily. Morocco uses the slogan "Sahara is Moroccan!" to highlight its sovereignty over the territory. Quite the contrary, The Polisario use slogans like "Sahara is free!" to disclaim Morocco's stance.

Transfer is another propaganda technique that is extensively used on both pro-Polisario and pro-Morocco websites. According to Lee and Lee (1939), transfer is used to link the reputation and power of an appreciated thing to another thing to make the latter more cherished. (p. 69). Propagandists often use the supremacy and power of something we respect to win our approval or sympathy. By using this technique, an attempt is made to convey the reputation of a certain symbol to an individual or an idea to make it more acceptable. Often highly visual, this technique repeatedly utilizes highly regarded symbols such as flags and emblems to transfer the respect people devote them to an event or an individual. An example of common use of this technique in those websites is for the Polisario leader Brahim Ghali photographed in front of the Polisario flag. Moroccan "waving flags" are frequently used as a backdrop for the Sahara map. Drawing on flags makes the implication that the incident is nationalistic in the best interest of the homeland .

One another example of propaganda devices used on the Sahara websites is Bandwagon. It is an appeal to the individual to follow the masses, to join in because others are doing so as well. Bandwagon centres on the theme all the people do and work together for the same thing. This technique attempts to convince us that all members of one group consent on idea and need to join them by getting on the bandwagon (Lee \& Lee 1939: 105). When talking about propaganda, Ellul (1973:150) emphasizes the significance of jumping in the bandwagon and joining the crowd: "everything is in the clutches of evil. There is a way out. But only if everybody participates" and "you must participate. If you don't, all will be lost, through your fault". In the Western Sahara conflict, this technique has served to rally people behind many political events. The Polisario, in many cases, uses the Bandwagon technique to induce young people into joining "the Sahrawis Popular Liberation Army". Morocco also makes use of this technique by calling for the people 
both domestically and internationally to join in and work together to help the Sahrawis who live in the Tindouf Camps.

One of the other main devices of propaganda is Plain Folks. Plain Folks refer to the technique through which a propagandist tries to persuade others that her or his ideas are beneficial because they are 'of the people' (Lee \& Lee 1939). By using Plain Folks, the propagandists attempt to give the impression that they are ordinary people just like the target audience by stressing the interests and feelings of common people. The plain Folks may involve a politician doing some common activities like visiting a church or praying in the mosque with ordinary people, going out running or playing with his kids. The technique occurs when an individual considers himself or herself as a member of common folk, not of an elite. The Plain Folks technique appeals to the need to of people to feel safe or comfortable and focuses on common language and image to instil the feeling of confidence among the target audience. An example of Plain Folks involves both Moroccan politicians and the Polisario leaders dressed in the traditional clothes of the Sahrawis and speak Hassania (the language of the Sahrawi population). In doing this, propaganda practitioners attempt to win the confidence of the target audience, by communicating in a common manner relative to the Saharan cultural context. This way of appearance gives the impression that their attitude mirrors the common sense. It is an attempt to induce people into endorsing a political event by making the audience get the feeling that those leaders share the same aspirations and struggle for the same goals.

Card stacking is one of the seven devices identified by the Institute for Propaganda Analysis (IPA). Card stacking is when a propagandist selects and employ both truths and untruths, evidences uncertainties, reasonable and irrational accounts to present the soundest or the worst aspect of an idea, individual, program or artifact (Lee \& Lee 1939: 95). Politicians often present only the negatives of their opponent and none of their positives. Conversely, they present their own positives and none of their negatives. The technique is used to persuade audiences and shape their opinion regarding a certain issue by stressing the positive aspects of that issue while hiding unwanted incidents. The most noticeable instance of card stacking can be noticed in case of the propaganda campaign launched on the Internet by Morocco and the Polisario shortly after the dismantling of Gdeim Izik camp and Laayoune events On 8 November 2010. A number of pro-Polisario websites claimed several civilian casualties and hundreds missing . Conversely, the Moroccan government declared that no civilian deaths were recorded during the dismantling of the Gdeim Izik camp. Another significant incident took place when a pro-Polisario website published a picture that depicts a murdered Moroccan family in Casablanca many years earlier and another picture of assassinated Palestinian children dating from 2006. Some pro-Polisario activists claimed the pictures belonged to a Sahrawi family and children killed as a result of what they called "the brutality of Moroccan forces". The photos were reused by the Spanish press to claim violence acts at the hands of Moroccan security forces, which was proven inauthentic soon after. In the context of Western Sahara Conflict, in which the issue of human rights is often raised when the opportunity arises, it is not surprising that the war of figures related casualties would be the basis of an extreme online propaganda campaign. Card-stacking is such a powerful technique for disseminating inaccurate data. Unfavourable statistics may be omitted and favourable ones are emphasized. Irrelevant truths are often hidden or censored. All this is done to slant a message, create an ambiguity among audiences and direct them at nothing but the intent of the propagandist.

Testimonial is also one of the most persuasive devices of propaganda. It is based on the idea that "big name" personalities are used to endorse a cause. Testimonials technique is used to make an appreciated or unloved individual disclose that a certain idea plan or person is good or bad (Lee \& Lee 1939: 74). When the testimony is provided by a popular celebrity, we are much less likely to be critical. Testimonials are frequently quotations given by a famous person or authority and exploited by propagandists to give credibility to their political cause. In the conflict of the Sahara, Testimonial is extensively used with great effect by Moroccan and Polisario propaganda experts. In their websites, propagandists of both conflicting parties focus on 
testimonies of prominent figures who adopt favourable opinion about the issue. In an earlier occasion, in an interview that appeared in a Dutch newspaper on 28th June, 2008, the UN Secretary-General's personal envoy and mediator in the Western Sahara conflict Peter Van Walsum declared that "An independent Sahrawi state is not a realistic option". Similarly, the former French minister of Culture and Education, Mr. Jack Lang, proclaimed that autonomy is " wise and reasonable solution to break the impasse". The testimony doesn't meet with the aspirations and views of the Polisario. The declarations evidently worked in favour of Morocco. Accordingly, the statement was extensively utilized by many pro-Morocco websites as strong argument to endorse Morocco's stance on the conflict. On the other hand, the most common use of the testimonial in pro-Polisario websites involves citing celebrities who endorse the Polisario stance on the Sahara issue. An example of pro-Polisario testimonial includes the testimony of the President of the General Assembly of the United Nations, Mr. Miguel d'Escoto Brockmann whose views on Western Sahara conflict were used by the Polisario propaganda practitioners and politicians to give credibility to their cause.

\section{CONCLUSION}

In the context of Western Sahara conflict, the use of propaganda through the Internet has been undoubtedly of a great benefit to the conflicting sides. With the increasing popularity of the Internet, the flow of persuasive messages has been dramatically accelerated and so the impacts of propaganda techniques cannot be underestimated. Both Moroccan and Polisario media professionals have exhibited a remarkable grasp of propaganda techniques. Propagandists have employed a range of techniques to win public support for their views on the issue. They have worked assiduously to rally public opinion behind the cause both domestically and overseas. Starting from the idea that "The new media are often depicted as the decisive causal link between a given crisis and the reaction of the international community" (Balabanova 2007: 14)) both sides have utilized propaganda abroad to influence foreign sentiment with the purpose of securing foreign countries' support or maintaining a positive image in front of the international community especially when human rights issues are arisen. Similarly, domestic propaganda appears to accomplish a parallel task in its messages. It has served to involve citizens in the conflict, boost morale, energize, mobilize and attempt to maintain incessant support for conflicting sides.

Although the ultimate objective of this study does not focus on a quantitative analysis of propaganda techniques, some reflections can be offered on the prevalence of these techniques. In this regard, varied manifestation of certain propaganda techniques on pro-Polisario websites has been observed. The technique of glittering generalities seems to be overriding through all websites under study. The dominance of this device can be explained by the prevailing existence of the technique in the form of seals, national emblems, and flags. Dependence on glittering generalities as propaganda device in this way may indicate that the propagandist doesn't give much priority to value judgment. In contrast, a lower use of the name-calling technique can be identified. The fact can be attributed to the conflicting parties' attempt to actively seek credibility ahead of their target audiences by adopting an official approach through their websites avoiding use of too critical and derogatory terminology when dealing issues related to the conflict.

In general, it seems that the different use of propaganda technique and their dominance depends on the situation that propagandists may experience and the goal they want to attain.

To end with, testing for the use of propaganda techniques has enabled us to have a look on a significant, tiny part of the huge mechanism of propaganda that is employed by both Moroccan and Polisario propaganda experts to guarantee control of the warfare online. This work aims at tackling a still very much unexplored field of research. The subject is so vast and far-reaching that it is little of it has been attempted and needs more attempts to evolve. 


\section{REFERENCES}

Abdi, R. (2002). Interpersonal metadiscourse as an indicator of interaction and identity. Discourse Studies. $4,139-145$.

Alarcon, J. B., \& Morales, K. N. S. (2011). Grammatical cohesion in students' argumentative essay. Journal of English and Literature, 2(5), 114-127.

Allen, A. (2002). "Just Whose Side Is God On?" British Journalism Review 13 (4): 41-50.

Balabanova, E. (2007). Media, wars and politics comparing the incomparable in Western and Eastern Europe. Aldershot, England: Ashgate.

Daadaoui, M. (2008). The Western Sahara conflict: towards a constructivist approach to selfdetermination. The Journal of North African Studies, 13(2), 143-156.

Ellul, J. (1973). Propaganda: the formation of men's attitudes. New York: Vintage Books

International Crisis Group (2007) 'Western Sahara: the costs of the conflict', Middle East/North Africa Report, 66, 11 June, Brussels/Cairo.

Jackall, R. (1995). How to Detect Propaganda. Propaganda, 217-224

Jowett, G., \& O'Donnell, V. (2015). Propaganda \& persuasion. Los Angeles: SAGE.

Kleinsteuber, H. (2004)" Comparing Mass Communication Systems: Media Formats, Media Contents, and Media Porcesses", in Esser, F., Pfetsch, B. (eds), Comparing Political Communication. Theories, Cases, and Challenges, Cambridge: Cambridge University Press. 64-86

Lee, A. \& Lee. (1939). The Fine Art of Propaganda: a study of Father Coughlin's speeches, New York: Harcourt Brace and Co.

Tankard, J., \& Severin, W. (1992). Communication Theories Origins, Methods, and Uses in the Mass Media. 3rd edn. New York: Longman.

Sproule, J. M. (1997). Propaganda and democracy: the American experience of media and mass persuasion. Cambridge,UK: Cambridge University Press.

Waters, G. (1983). Media Analysis Techniques Arthur Asa Berger. Film Quarterly, 37(1), 53-53.
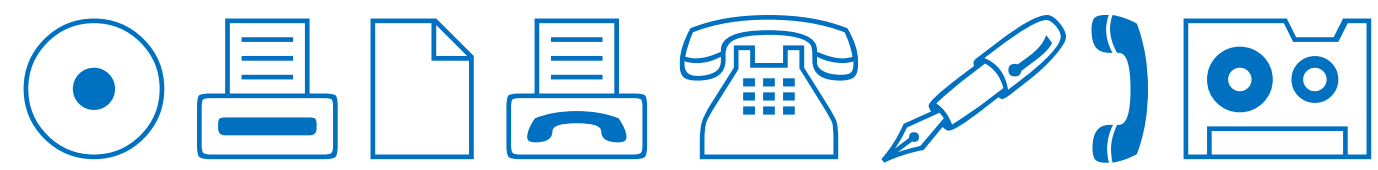